\title{
Manometric findings in relation to functional outcomes in different types of anorectal malformations
}

\section{Kyrklund, Kristiina}

2017-04

Kyrklund , K , Pakarinen, M P \& Rintala , R J 2017 , ' Manometric findings in relation to functional outcomes in different types of anorectal malformations ' , Journal of Pediatric Surgery, vol. 52 , no. 4 , pp. 563-568 . https://doi.org/10.1016/j.jpedsurg.2016.08.025

http://hdl.handle.net/10138/236996

https://doi.org/10.1016/j.jpedsurg.2016.08.025

publishedVersion

Downloaded from Helda, University of Helsinki institutional repository.

This is an electronic reprint of the original article.

This reprint may differ from the original in pagination and typographic detail.

Please cite the original version. 


\title{
Manometric findings in relation to functional outcomes in different types of anorectal malformations ${ }^{2}$, 弥访, $\star$
}

\author{
Kristiina Kyrklund *, Mikko P. Pakarinen, Risto J. Rintala \\ Department of Pediatric Surgery, Hospital for Children and Adolescents, University of Helsinki
}

\section{A R T I C L E I N F O}

\section{Article history:}

Received 19 June 2016

Received in revised form 18 August 2016

Accepted 21 August 2016

\section{Key words:}

Anorectal malformations

Anorectal manometry

Fecal continence

Bowel function

Internal anal sphincter

\begin{abstract}
A B S T R A C T
Aims: To compare anorectal manometry (AM) in patients with different types of anorectal malformations (ARMs) in relation to functional outcomes.

Methods: A single-institution, cross-sectional study. After ethical approval, all patients $\geq 7$ years old treated for anterior anus (AA), perineal fistula (PF), vestibular fistula (VF), or rectourethral fistula (RUF) from 1983 onwards were invited to answer the Rintala bowel function score (BFS) questionnaire and to attend anorectal manometry (AM). Patients with mild ARMs (AA females and PF males) had been treated with minimally invasive perineal procedures. Females with VF/PF and males with RUF had undergone internal-sphincter saving sagittal repairs. Results: 55 of 132 respondents (42\%; median age 12 (7-29) years; 42\% male) underwent AM. Patients with mild ARMs displayed good anorectal function after minimally invasive treatments. The median anal resting and squeeze pressures among patients with mild ARMs ( $60 \mathrm{~cm} \mathrm{H2O}$ and $116 \mathrm{~cm} \mathrm{H2O} \mathrm{respectively)} \mathrm{were} \mathrm{significantly} \mathrm{higher} \mathrm{than}$ among patients with more severe ARMs ( $50 \mathrm{~cm} \mathrm{H2O}$, and $80 \mathrm{~cm} \mathrm{H2O} \mathrm{respectively;} p \leq 0.002$ ). The rectoanal inhibitory reflex was preserved in $100 \%$ of mild ARMs and $83 \%$ of patients with more severe malformations after IASsaving sagittal repair. The functional outcome was poor in $4 / 5$ patients with an absent RAIR (BFS $\leq 11$ or antegrade continence enema-dependence). Rectal sensation correlated significantly with the BFS.

Conclusions: Our findings support the appropriateness of our minimally invasive approaches to the management of mild ARMs, and IAS-saving anatomical repairs for patients with more severe malformations. Level of evidence: III.
\end{abstract}

(c) 2017 Elsevier Inc. All rights reserved.
Internal anal sphincter (IAS)-saving sagittal repair methods, including posterior sagittal anorectoplasty (PSARP) for rectourethral fistula (RUF) in males, and anterior sagittal anorectoplasty (ASARP) for females with vestibular and perineal fistula (VF/PF) are standardized approaches for the anatomical reconstruction of anorectal malformations (ARMs) with a fistulous termination of the bowel outside the external anal sphincter (EAS) complex at our institution and others [1,2]. For mild ARMs with a bowel termination mostly within the EAS such as anterior anus (AA) in females and standard perineal fistula (PF) in males, our approach has been minimally invasive, involving serial dilatations

Abbreviations: ARM, anorectal malformation; AM, anorectal manometry; AA, anterior anus; PF, perineal fistula; VF, vestibular fistula; RUF, rectourethral fistula; EAS, external anal sphincter; IAS, internal anal sphincter; PSARP, posterior sagittal anorectoplasty; ASARP, anterior sagittal anorectoplasty.

it Conflicts of interest: None to declare

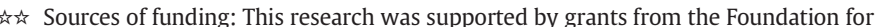
Pediatric Research (Finland), the Sigrid Juselius Foundation, and the Helsinki University Central Hospitals research funds.

$\star$ The abstract for this manuscript was presented at the European Pediatric Surgeon's Association Congress in Rome Italy, 17-20.6.2015.

* Corresponding author at: Department of Pediatric Surgery, Hospital for Children and Adolescents, University of Helsinki, PL 281, 00029, HUS, Helsinki, Finland. Tel.: + 35850 427 0450; fax: + 358947175314 .

E-mail address: kristiina.kyrklund@hus.fi (K. Kyrklund). or conservative follow-up only for AA females, and cutback anoplasty for males with PF [3,4] to achieve a satisfactory passage of stool [5].

We recently published the controlled, long-term bowel functional outcomes by type of ARM for these patients [3,4,6,7]. We found bowel function mostly comparable to matched peers in mild ARMs [3,4], and the majority of patients with more severe ARMs achieved social continence with appropriate aftercare [6,7]. Some degree of functional impairment, however, persisted in approximately $1 / 3$ of females with $\mathrm{VF} / \mathrm{PF}$, and in $2 / 3$ of males with RUF [6,7].

This study has aimed to objectively uncover the reasons behind the functional impairments observed, particularly among patients with severe ARMs. The findings of AM by type of ARM require further characterization. We performed manometric evaluation of patients with different types of ARMs after standardized treatments, comparing the findings with patient-reported clinical outcomes. To our knowledge, this is one of the largest single-centre studies of AM in ARM patients to date.

\section{Methods}

\subsection{Patients}

After ethical approval, all patients treated at our institution between 1983 and 2006 for AA, PF, VF and RUF were cross-sectionally invited to 
answer a detailed postal questionnaire on bowel function. All consenting participants $\geq 7$ years of age were also invited to undergo anorectal manometry (AM) as outpatients. Patients with major cognitive impairment, severe sacral anomalies ( $<3$ segments remaining), Currarino syndrome or meningomyelocele were excluded. Participation was voluntary. Operative and case details were obtained retrospectively from records. A single independent investigator conducted the survey and AM. The investigator, an experienced clinician, had not been involved in any aspect of the surgical or medical management of the patients.

\subsection{Questionnaires}

Bowel function was evaluated using the Rintala bowel function score (BFS) [8], for which a close correlation with clinical outcomes has been established cohorts [8-10], and a large pool of control data is available [11]. A BFS of $\geq 17 / 20$, achieved by $\geq 90 \%$ of controls [11] was taken as the lower limit of normal.

\subsection{Manometric equipment and technique}

AM was performed using a saline-perfused 4-channel catheter $\left(0.2 \mathrm{ml} / \mathrm{min}\right.$; pressure rise rate $100 \mathrm{~cm} \mathrm{H}_{2} \mathrm{O} / \mathrm{s}$ ) with 4 spirally placed side openings ( $4.5 \mathrm{~mm}$ outer diameter) at $1 \mathrm{~cm}$ intervals near the tip. Measurements were taken using transducers in each line connected to a personal computer. The machine (Medtronic Polygram 98; Medtronic Functional Diagnostics, Skovlunde Denmark) was calibrated separately for each patient. Patients performed a rectal enema at home the preceding evening. AM was performed without sedation with the patient in the left lateral decubital position with the knees and hips flexed. The lubricated catheter was introduced $10 \mathrm{~cm}$ into the rectum and withdrawn by continuous pull-through technique at a rate of $1 \mathrm{~mm} / \mathrm{s}$.

\subsection{Manometric recordings}

The length of the anal canal high-pressure zone (HPZ) was defined as the distance between the proximal margin of the HPZ, indicated by a rise in the anal canal pressure, and the anal outlet characterized by a pressure drop in the distal HPZ to $50 \%$ of the maximum [12]. The anal canal resting pressure (ARP) was taken as the mean static pressure when the catheter was placed in the HPZ for $1 \mathrm{~min}$ [13]. The anal squeeze pressure (ASP) was taken as the maximum of 3 attempts when the patient was asked to contract their anal sphincter around the catheter [14].

\subsection{Rectoanal inhibitory reflex (RAIR) and rectal sensory threshold (RST)}

RAIR was provoked by inserting a second catheter containing a latex balloon at a distance of $10 \mathrm{~cm}$ from the anal verge and incrementally insufflating the balloon starting from $10 \mathrm{ml}$ of air with the manometry catheter in the HPZ [12-14]. A RAIR was considered to be present if the anal canal pressure dropped by at least $25 \%$ of the basal tone over at least $5 \mathrm{~s}$. The rectal sensory threshold (RST) was taken as the mean value of 3 gradual fillings after asking the patient to indicate as soon as they perceived the balloon.

\subsection{Reference values for manometric data used in this study}

The reported normal values for the HPZ in children and adults have ranged from 2 to $4 \mathrm{~cm}$ depending on age [14-17]. For pressure reference values, we used data reported from 17 controls aged 8-17 years who underwent AM at our institution using the same technique: ARP 60 (45-80), ASP 120 (80-184), and 100\% for RAIR [18]. AM had been performed by our two senior pediatric colorectal surgeons. As previously reported normal values for RST have ranged been $<15-20 \mathrm{ml}[12,19]$, $>20 \mathrm{ml}$ was considered indicative of reduced rectal sensation.

\subsection{Statistics}

Data are presented as median (range). Categorical variables were compared using Fisher's exact test, and continuous variables using the Mann-Whitney $U$ test. Spearman's correlation coefficient was used to test the correlation between manometric variables and the functional outcome by BFS. A two-tailed $p$-value $<0.05$ was considered statistically significant.

\section{Results}

\subsection{Participants}

The main patient characteristics are shown in Fig. 1. Of 132 survey participants aged $\geq 7$ years, 55 patients (42\%; median age 12 (7-28) years) agreed to AM. All patients had been treated and systematically followed up by the same surgical team from birth and none had been lost to follow-up. Constipation was treated using dietary modifications, laxatives and/or enemas as appropriate. Ten patients (18\%) had mild sacral dysplasia ( $\geq 3$ segments remaining), including $0 \%$ of females with AA, 1 male with $\mathrm{PF}(8 \%), 4$ females with $\mathrm{VF} / \mathrm{PF}(19 \%)$ and 5 males with RUF (50\%).

\subsection{Surgical management}

All 11 females with AA had been managed non-operatively [3]. Five (45\%) had been treated for mild anal stenosis with Hegar dilatations from size 11 to 14 . In females, termination of the anal canal mostly within the external sphincter complex (distinguishing AA from PF) was confirmed using an electrical muscle stimulator under anesthesia if this had been clinically unclear [3]. All males with PF had received standard cutback anoplasty on the first day of life [4]. Females with VF/PF had undergone internal sphincter-saving ASARP [6] with conservation of the distal part of the fistulous bowel termination at a median of 1.1 (range, 0.1-11) months of age; 7 (33\%) under colostomy cover. RUF patients (30\% bulbar fistula $(n=3)$; $50 \%$ prostatic fistula $(n=5)$, and $20 \%$ bladderneck fistula $(n=2)$ ) had been treated with internal sphinctersaving PSARP [7] after primary colostomy at a median age of 2 (range, 1-10) months. All operatively managed patients had undergone a standard anal dilatation program over 6 weeks up to Hegar size 14, after which any colostomies were closed.

\subsection{Postoperative complications and late operations}

One male with PF had anoplasty for residual stenosis at 1 year of age. One female with VF required revision of ASARP at the age of 5 years. This patient suffered from intractable constipation, which led to gradual perineal body breakdown. Hirschsprung's disease was histologically excluded. She and two others (1 VF female and 1 RUF male) also underwent resection of a megarectum later in childhood. Three males with RUF (5\% of 55 AM participants) aged 9, 10 and 28 years had antegrade continence enema (ACE) conduits for social continence (1 bladderneck and 2 prostatic fistulas).

\subsection{Non-participants}

Of the 77 patients who had participated in the survey but declined AM (Fig. 1), patient characteristics including gender (56\% male), median age (13 range, $7-29$ years), and percentage with sacral dysplasia (10\%) or ACE conduits ( $8 \%$ ) were not significantly different from survey respondents who underwent AM ( $p \geq 0.21$ for all comparisons). The types of ARMs (31\% AA females, 31\% PF males, and 25\% RUF males) were also comparable ( $p=\mathrm{NS}$ ), apart from a higher proportion of $\mathrm{VF} / \mathrm{PF}$ females in the AM group (13\% vs 38\%; $p=0.002$ ). The baseline characteristics of the 63 patients who did not participate any aspect of the study were not significantly different from survey respondents ( $p=$ NS for all comparisons). 


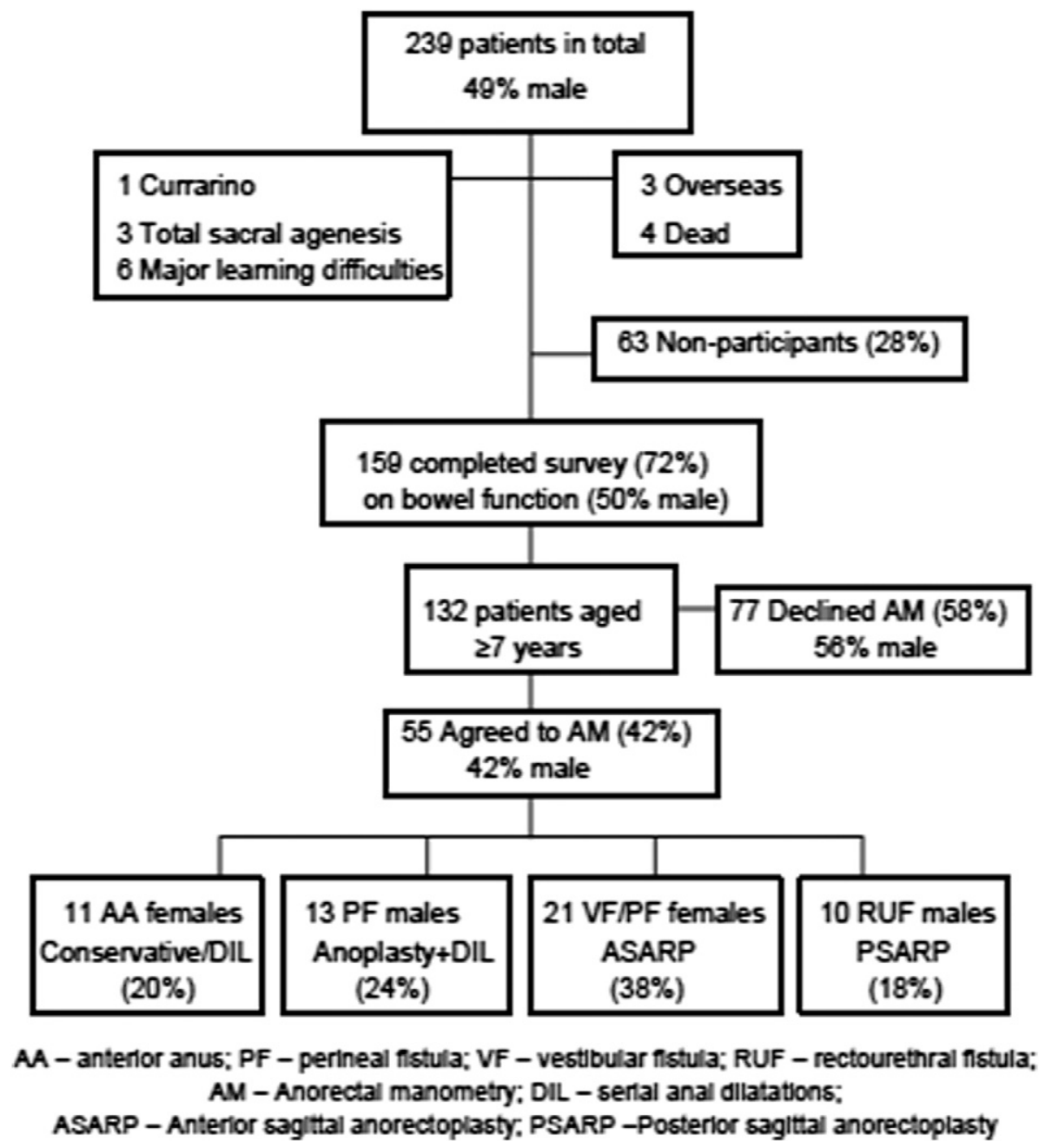

Fig. 1. Patient characteristics.

\subsection{Manometric data and comparison to reference values}

The manometric parameters by type of ARM are shown in Table 1. Males with RUF had the lowest recordings for all measurements, and these were all significantly inferior to AA females $(p \leq 0.04)$. Approximately $2 / 3$ of patients with PF, VF and RUF had a decreased HPZ of $<2.0 \mathrm{~cm}$ ( $p \leq 0.02$ vs AA females). The HPZ was $<1.5 \mathrm{~cm}$ in $8 \%$ patients with mild ARMs (AA females and PF males; $n=2$ males with PF), 19\% of females with $\mathrm{VF} / \mathrm{PF}(\mathrm{n}=4)$ and $40 \%$ of males with RUF $(\mathrm{n}=4 ; p=$ 0.047 for RUF vs mild ARMs; $p=$ NS between other ARMs) The median ARP and ASP among patients with mild ARMs (60 cm H2O and $116 \mathrm{~cm}$
$\mathrm{H} 2 \mathrm{O}$ respectively) were significantly higher than among patients with more severe ARMs ( $50 \mathrm{~cm} \mathrm{H} 2 \mathrm{O}$, and $80 \mathrm{~cm} \mathrm{H}_{2} \mathrm{O}$ respectively; $p \leq 0.002$ ).

The ARP was below the lowest value in controls from the reference series [18] in 14 patients overall: 1 male with PF (4\% of mild ARMs), 7 (33\%) of VF/PF females and 6 (60\%) of RUF males. The ASP was concurrently subnormal in 13/14 of these cases: 1 male with PF (4\% of mild ARMs), 6 (29\%) of VF/PF females and 6 (60\%) of RUF males (60\%). Resting and squeeze pressures inferior to the lowest value in controls were significantly more common among patients with more severe ARMs who had undergone sagittal repairs $(n=12 / 31 ; 39 \%)$ than among patients with mild ARMs $(1 / 24 ; 4 \% ; p \leq 0.02)$.

Table 1

Manometric parameters by type of ARM.

\begin{tabular}{|c|c|c|c|c|c|}
\hline \multirow[b]{2}{*}{ ARM } & \multirow[b]{2}{*}{$\mathrm{n}$} & \multicolumn{4}{|c|}{ Value, median (range) or n (\%) } \\
\hline & & $\mathrm{HPZ}, \mathrm{cm}$ & $\mathrm{HPZ}<2.0 \mathrm{~cm} \mathrm{n} \mathrm{( \% )}$ & ARP $\mathrm{cm} \mathrm{H} 2 \mathrm{O}$ & ASP cm H2O \\
\hline AA females & 11 & $2.2(1.5-2.7)^{*}$ & $1(9)^{*}$ & $65(50-80)^{*}$ & $120(106-180)^{* * *}$ \\
\hline PF males & 13 & $1.8(1.5-2.3)$ & $9(69)$ & $60(45-75)^{9}$ & $110(75-150)^{99}$ \\
\hline VF/PF females & 21 & $1.8(1.5-2.3)$ & $15(71)$ & $50(35-75)$ & $81(44-150)$ \\
\hline RUF males & 10 & $1.7(1.0-2.0)$ & $6(60)$ & $25(24-75)$ & $73(20-150)$ \\
\hline
\end{tabular}

$\mathrm{HPZ}$ - high pressure zone; ARP - anal resting pressure; ASP - anal squeeze pressure.

$p=$ NS between groups unless otherwise stated; Mann-Whitney $U$ test.

$* p \leq 0.03$ vs other ARM types.

** $p=0.09$ vs PF males and $\leq 0.02$ vs VF/PF females and RUF males.

${ }_{9} p=0.07$ vs RUF males.

g9 $p=0.002$ vs VF females and 0.09 vs RUF males. 
Table 2

RAIR and rectal sensation by type of ARM.

\begin{tabular}{|c|c|c|c|c|c|}
\hline ARM & $\mathrm{n}$ & RAIR present, \% & Median RST, ml (range) & $\mathrm{RST}>20 \mathrm{ml}, \mathrm{n}(\%)$ & Abnormal RST + constipation $\mathrm{n}(\%)$ \\
\hline AA females & 11 & $100^{*}$ & $10(10-10)^{* *}$ & $0^{* * *}$ & 0 \\
\hline PF males & 13 & $100^{9}$ & $10(10-80)^{99}$ & $2(15)$ & $2(15)$ \\
\hline VF/PF females & 21 & 90 & $18(10-150)$ & $6(29)$ & $5(24)$ \\
\hline RUF males & 10 & 70 & $25(10-150)$ & $5(50)$ & $4(40)$ \\
\hline
\end{tabular}

RST rectal sensation threshold; RAIR - Rectoanal inhibitory reflex

$* p=0.09$ vs RUF males.

** $p \leq 0.03$ vs RUF males and VF/PF females.

*** $p=0.01$ vs RUF males and 0.07 vs VF/PF females.

${ }^{g} p=0.07$ vs RUF males.

g9 $p=0.03$ vs RUF males.

Table 3

Manometric findings and BFS among patients with absent RAIR $(\mathrm{n}=5)$.

\begin{tabular}{|c|c|c|c|c|c|c|c|c|c|}
\hline Case & ARM & $\mathrm{M} / \mathrm{F}$ & Age & ACE & $\mathrm{HPZ} \mathrm{cm}$ & ARP cm H2O & ASP cm H2O & RST ml & $\mathrm{BFS} / 20$ \\
\hline 1 & VF & $\mathrm{F}$ & 15 & $\mathrm{No}^{*}$ & 1.1 & 35 & 50 & - & 11 \\
\hline 2 & VF & $\mathrm{F}$ & 27 & No & 1.5 & 38 & 75 & 20 & 20 \\
\hline 3 & $\operatorname{RUF}(B)^{g}$ & M & 7 & No & 2.0 & 60 & 133 & 50 & 11 \\
\hline 4 & RUF $(P)^{g}$ & M & 11 & Yes & 1.0 & 20 & 50 & 80 & ACE \\
\hline 5 & $\operatorname{RUF}(B N)^{g}$ & M & 27 & Yes & 1.0 & 24 & 30 & 15 & ACE \\
\hline
\end{tabular}

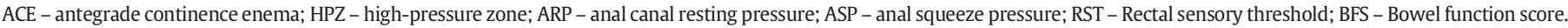

* patient declined ACE.

9 B - bulbar fistula; P - prostatic fistula; BN - bladderneck fistula.

The surveyed functional outcomes for the 12 patients with sagittal repairs and reduced ARP and ARP on AM were further assessed: The BFS was in the normal range ( $\geq 17 / 20)$ in $4 / 12$ patients (33\%), who were all females with VF/PF. The RST and RAIR were also normal in 3 of these 4 females. The BFS was abnormal (range, 7-16) in the remaining 8 patients (67\%; 6 RUF males and $2 \mathrm{VF} / \mathrm{PF}$ females), of whom $4 / 8$ had a poor BFS $(\leq 11)$ and/or were ACE-dependent for social continence. Furthermore, $5 / 8$ also had decreased rectal sensation and $3 / 8$ had an absent RAIR.

\subsection{RAIR by type of ARM}

The proportion of patients exhibiting RAIR by type of ARM is shown in Table 2. RAIR was present in 91\% (50/55) of patients, including all patients with mild ARMs and no bowel mobilization surgery and 83\% (26/31) of patients treated with sagittal repairs ( $p=0.06$ between groups). RAIR was absent in the female with VF who had undergone re-do ASARP, and in 3 males with RUF (of whom 2 had required ACE conduits). RAIR could also not be elicited in one adult female with VF who reported unimpaired bowel function (BFS 20/20). The manometric results and BFS for the 5 patients with absent RAIR are presented in Table 3. Although the BFS could not be calculated from the questionnaire for the patients with ACE, they were dependent on regular washouts for social continence.

\subsection{Rectal sensory threshold (RST)}

Results for RST by type of ARM are shown in Table 2 . Thirteen patients (24\%) in total had an abnormal RST (>20 ml): 2(15\%) males with PF, 6 (29\%) females with VF/PF, and 5 (50\%) males with RUF. Concurrent constipation was present in $85 \%(n=11 / 13)$ of patients with an abnormal RST (Table 2). This was diet-controlled in 2 (18\%) and managed with laxatives or enemas in the remainder $(n=9 / 11)$. As shown in Table 4, soiling, fecal accidents and constipation were significantly more common among patients with reduced rectal sensation than those with a normal RST $(p \leq 0.004)$.

\subsection{Correlation with bowel functional outcomes}

Of the manometric parameters - length of HPZ, ARP, ASP and rectal sensation, only rectal sensation correlated significantly with the BFS (Fig. $2 ; p<0.001$; rho -0.46 ).

\subsection{Mild sacral dysplasia and AM}

The effect of mild sacral dysplasia (3-4 segments remaining) assessed among patients with more severe ARMs (i.e VF/PF females and RUF males) in whom the prevalence was $29 \%$ ( $n=9 / 31)$, as only 1 patient with a mild ARM (4\%) had a dysplastic sacrum. As shown in Table 5, no significant differences were noted between groups on AM.

\section{Discussion}

Anorectal manometry (AM) is a minimally invasive and readily available instrument for the objective assessment of anorectal function [20]. This study has aimed to describe the findings of AM among patients with different types of ARMs in relation to the clinical outcomes. All patients had undergone standardized management of the ARM by the same surgical team, who had also followed them up. AM was conducted by an independent clinician who had not cared for the patients.

In our series, the females with AA have a very mild ARM and have not had any form of operative treatment. Although PF males had undergone minor cutback anoplasty, no bowel mobilization surgery had been performed. For these ARMs, the manometric measurements for anal resting and squeeze pressures (Table 1 ) in both groups essentially corresponded to the values reported among controls in our reference series [18]. As with the reference controls [18], a RAIR was present in all patients with mild ARMs, consistent with a functional IAS [21]. Although two thirds of males with PF had a shortened HPZ of $<2 \mathrm{~cm}$ (Table 1) on manometry, this was not reflected in the functional

Table 4

Functional symptoms and rectal sensory threshold (RST).

\begin{tabular}{llll}
\hline & \multicolumn{2}{l}{ RST } & \\
\cline { 2 - 4 } Symptom $^{\mathrm{g}}$ & Normal $^{*}(\mathrm{n}=42)$ & Abnormal $(\mathrm{n}=13)$ & $p$ \\
\hline Soiling, $\mathrm{n}(\%)$ & $16(38)$ & $11(85)$ & 0.004 \\
Fecal accidents, $\mathrm{n}(\%)$ & $4(10)$ & $8(62)$ & $<0.0001$ \\
Constipation, $\mathrm{n}(\%)$ & $10(24)$ & $11(85)$ & $<0.0001$ \\
Median BFS (range) & $19(14-20)^{* *}$ & $16(7-20)^{* * *}$ & 0.001 \\
\hline
\end{tabular}

g Any impairment of function for soiling, fecal accidents and constipation.

* Normal taken as $\leq 20 \mathrm{ml}$

** Of 41 patients: BFS could not be calculated for 1 patient with ACE.

*** Of 11 patients: BFS could not be calculated for 2 patients with ACE. 

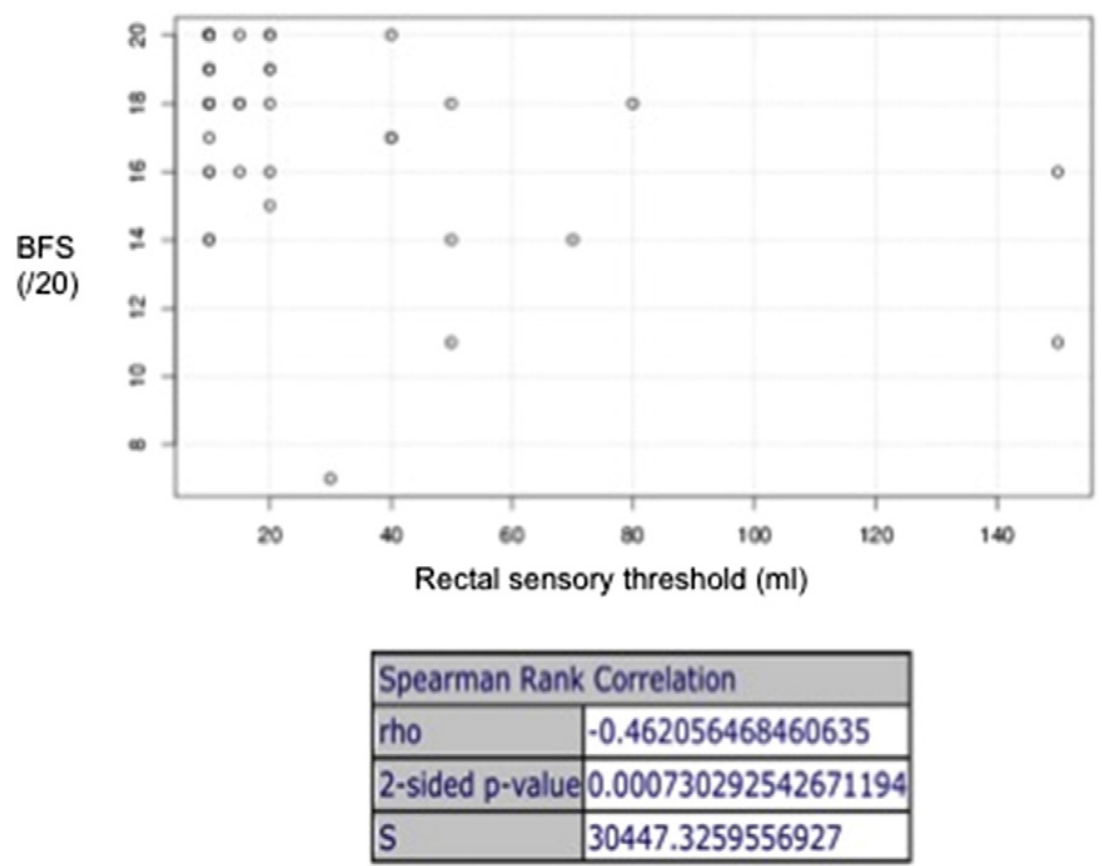

Fig. 2. Spearman's rank correlation plot of RST compared to BFS.

outcomes and an HPZ $<1.5 \mathrm{~cm}$ was uncommon (15\% of mild ARMs). Rectal sensation was predominantly normal in both AA and PF males, consistent with the good clinical outcomes we have previously reported $[3,4]$ and further supporting the appropriateness of our minimally invasive treatment approaches for these ARM types [3,4].

The females with VF/PF and males with RUF all underwent IASsaving sagittal repairs, entailing preservation of the distal fistulous bowel termination, with full PSARP in males and ASARP (also known as limited PSARP) in females. Functionally, the IAS accounts for up to 85\% of the ARP [23]. Efficacy of the external anal sphincter (EAS), which maintains urge fecal continence, is reflected in the ASP [22,23]. Approximately $1 / 3$ of females with VF/PF and nearly $2 / 3$ of RUF males had both an ARP and ASP below the lowest values among our reference subjects [18]. This compares with just one patient with a mild ARM ( $4 \%$; $p \leq 0.02$ vs patients with more severe ARMs), suggesting a greater effect on sphincter pressures with increasing severity of ARM.

With regard to fecal continence, while all 6 RUF males with reduced pressure recordings had a $\mathrm{BFS}<17$, and $5 / 6(83 \%)$ reported difficulties withholding defecation, 4/6 (67\%) of the females with VF/PF and reduced pressure recordings had a BFS in the normal range, and only 1 reported difficulties withholding defecation. Although we were unable to demonstrate a statistically significant difference between the AM results of RUF males and VF/PF females in our series, this is more likely to be because of the limited patient numbers rather than an absence of actual differences between these patient groups. The contrasting clinical outcomes would support greater impairment of the ARP (median $25 \mathrm{~cm}$ $\mathrm{H} 2 \mathrm{O}$ in RUF and $50 \mathrm{~cm} \mathrm{H} 2 \mathrm{O}$ in VF/PF) and greater shortening of the HPZ among RUF males ( $<1.5 \mathrm{~cm}$ in $40 \%$ of RUF vs $19 \%$ of VF/PF patients), consistent with more significant hypoplasia. In the literature, an association between continence and the ARP $[8,21,22,24]$ or ASP [25] has been reported, but also the absence of a correlation with either of these $[26,27]$. Limitations of our study are the relatively small numbers of patients by type of ARM, and the small number of controls available.

Among our 8 patients with reduced ARP/ASP and a subnormal BFS $(<17)$, RAIR was not observed in $38 \%$, consistent with significant IAS impairment. Furthermore, rectal sensation was also abnormal in $62 \%$ of these, demonstrating multiple concurrent abnormalities among the same patients in association with a reduced functional outcome. Fortunately, RAIR was preserved among $83 \%$ of patients after IAS-saving bowel mobilization surgery (Table 2 ), including $90 \%$ of females with $\mathrm{VF} / \mathrm{PF}$ and $70 \%$ of males with RUF. The presence of a RAIR is regarded to be indicative of functional IAS tissue [21], and its conservation is considered important in the modern management of ARMs [13,22]. Classical sacroperinal or sacroabdominoperineal operations, which involved resection of the terminal fistulous connection, led to loss of the IAS and RAIR and inferior outcomes compared to PSARP [13]. Indeed, 4/5 of our patients in whom RAIR was not detected also had ARP $(\leq 38 \mathrm{~cm}$ H2O; Table 3) and severely impaired fecal continence (BFS 11 or requirement for ACE). Our manometric data thereby supports the notion that functional IAS tissue is present in the distal fistulous bowel termination in ARMs [28], and that its preservation may influence the continence outcomes. Multi-centre studies involving larger numbers of patients are needed to confirm the findings.

The RST was abnormal among $29 \%$ of females with VF and $50 \%$ of males with RUF (Table 2), with a significantly increased median RST among males with RUF compared to females with AA and PF males

Table 5

Effect of mild sacral dysplasia and manometric parameters and BFS among patients with severe ARMs (VF/PF females and RUF males).

\begin{tabular}{|c|c|c|c|c|c|c|c|c|c|}
\hline \multirow[b]{2}{*}{ Sacrum } & \multirow[b]{2}{*}{$\mathrm{n}$} & \multirow[b]{2}{*}{ RUF \% } & \multicolumn{4}{|c|}{ Value, median (range) } & \multirow[b]{2}{*}{ RAIR present n (\%) } & \multirow[b]{2}{*}{ Normal RST n(\%) } & \multirow[b]{2}{*}{ Median BFS (range) } \\
\hline & & & Age, y & $\mathrm{HPZ}, \mathrm{cm} \mathrm{H} 2 \mathrm{O}$ & ARP, cm H2O & ASP, cm H2O & & & \\
\hline Dysplasia & 9 & 55 & 15 & $1.8(1-2.3)$ & $35(20-65)$ & $60(20-133)$ & $4(55)$ & $4(44)$ & $147-20$ \\
\hline Normal & 22 & 33 & 11 & $1.8(1-2.2)$ & $50(35-80)$ & $82(44-150)$ & $20(95)$ & $14(66)$ & $1714-20$ \\
\hline$p$ & & 0.15 & 0.52 & 0.77 & 0.08 & 0.10 & 0.06 & 0.41 & 0.11 \\
\hline
\end{tabular}

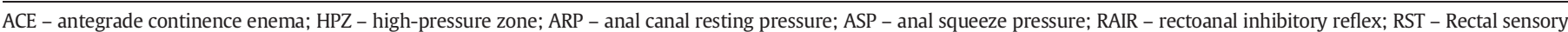
threshold; BFS - Bowel function score. 
( $p \leq 0.03$ ), and among VF patients compared to AA females ( $p \leq 0.03)$. Both soiling (85\%) and fecal accidents (62\%) were significantly more common among patients with an abnormal RST compared to patients with normal rectal sensation $(p \leq 0.004)$, and the BFS was significantly reduced $(p=0.001)$. Decreased rectal sensitivity has been correlated with a poor functional outcome in several series $[22,26]$.

Another important observation was that constipation coexisted among patients with decreased rectal sensation in $85 \%$ of cases (Table 4 ), being significantly more common than among patients with a normal RST $(p<0.0001)$. Although rectal sensation correlated with the functional outcome by BFS ( $p<0.001$ ), it is not possible to establish whether constipation was the cause or effect of reduced rectal sensation in this retrospective series. While studies have suggested that a normal RST is not essential for fecal continence [29,30], abolition of anal canal sensation reduces the force and duration of contraction of the external sphincter $[29,30]$. However, the same treatment does not appear to affect the threshold for RAIR or subsequent recovery of internal sphincter tone $[29,30]$, which, in theory, protects against fecal incontinence.

Although severe sacral defects reduce the continence outlook in ARM patients because of significant associated spinal dysraphism [31,32], our data did not suggest that mild sacral dysplasia (3-4 segments remaining) had any demonstrable effect on the AM profile (Table 5).

\section{Conclusions}

In this study, we undertook a detailed evaluation of the findings of AM among patients with different types of ARMs in comparison to the clinical outcomes. AM effectively demonstrated good anorectal function in mild ARMs with a good outcome, and multiple concurrent abnormalities among most patients with more severe ARMs and impaired bowel function. With regard to fecal continence, our findings support the appropriateness of our minimally invasive approaches to the management of mild ARMs, and IAS-saving anatomical repairs for patients with more severe malformations.

\section{References}

[1] Rintala RJ, Pakarinen MP. Outcome of anorectal malformations and Hirschsprung's disease beyond childhood. Semin Pediatr Surg 2010;19:160-7.

[2] Wakhlu A, Kureel SN, Tandon RK, et al. Long-term results of anterior sagittal anorectoplasty for the treatment of vestibular fistula. J Pediatr Surg 2009;44: 1913-9.

[3] Kyrklund K, Pakarinen MP, Taskinen S, et al. Bowel function and lower urinary tract symptoms in females with anterior anus treated conservatively: controlled outcomes up to adulthood. J Pediatr Surg 2015;50:1168-73.

[4] Kyrklund K, Pakarinen MP, Taskinen S, et al. Bowel function and lower urinary tract symptoms in males with low anorectal malformations: an update of controlledlong-term outcomes. Int J Colorectal Dis 2015;30:221-8.

[5] Pakarinen MP, Rintala RJ. Management and outcome of low anorectal malformations. Pediatr Surg Int 2010;26:1057-63.

[6] Kyrklund K, Pakarinen MP, Koivusalo A, et al. Bowel functional outcomes in females with perineal or vestibular fistula treated with anterior sagittal anorectoplasty: controlled results into adulthood. Dis Col Rectum 2015;58:97-103.
[7] Kyrklund K, Pakarinen MP, Koivusalo A, et al. Long-term bowel functional outcomes in rectourethral fistula treated with PSARP: controlled results after 4-29 years of follow-up: a single-institution, cross-sectional study. J Pediatr Surg 2014;49: $1635-42$.

[8] Rintala RJ, Lindahl HG. Is normal bowel function possible after repair of intermediate and high anorectal malformations? J Pediatr Surg 1995;30:491-4.

[9] Jarvi K, Laitakari EM, Koivusalo A, et al. Bowel function and gastrointestinal quality of life among adults operated for Hirschsprung disease during childhood: a population-based study. Ann Surg 2010;252:977-81.

[10] Pakarinen MP, Koivusalo A, Lindahl H, et al. Prospective controlled long-term followup for functional outcome after anoplasty for boys with perineal fistula. J Pediatr Gastroenterol Nutr 2007:44:436-9.

[11] Kyrklund K, Koivusalo A, Rintala RJ, et al. Evaluation of bowel function and fecal continence in 594 Finnish individuals aged 4 to 26 years. Dis Col Rectum 2012;55: 671-6.

[12] Pakarinen MP, Koivusalo A, Rintala RJ. Functional fecal soiling without constipation, organic cause or neuropsychiatric disorders? J Pediatr Gastroenerol Nutr 2006;43: 206-8.

[13] Rintala RJ, Lindahl HG. Posterior sagittal anorectoplasty is superior to sacroperinealsacroabdominoperineal pull-through: a long-term follow-up study in boys with high anorectal anomalies. J Pediatr Surg 1999;34:334-7.

[14] Kumar S, Ramadan S, Gupta V, et al. Manometric tests of anorectal function in 90 healthy children: a clinical study from Kuwait. J Pediatr Surg 2009;44:1786-90.

[15] Pfeifer J, Oliveira L. In: Wexner SD, Duthie G, editors. Constipation: etiology, evaluation and management. London, UK: Springer-Verlag Publ.; 2006. p. 72-83.

[16] Keshtgar AS, Choudhury MS, Kufeji D, et al. Anorectal manometry with and without ketamine for evaluation of defecation disorders in children. J Pediatr Surg 2015;50: 438-43.

[17] Ambarsumyan MD, Rodriguez L, Morera C, et al. Longitudinal and radial characteristics of intra-anal pressures in children using 3D anorectal manometry: new observations. Am J Gastroenterol 2013:1918-28.

[18] Rintala RJ, Lindahl HG. Fecal continence in patients having undergone posterior sagittal anorectoplasty procedure for a high anorectal malformation improves at adolescence, as constipation disappears. J Pediatr Surg 2001;36:1218-21.

[19] Rao SS, Hatfield R, Soffer E, et al. Manometric tests of anorectal function in healthy adults. Am J Gastroenterol 1999;94:774-83.

[20] Wang Z, Jin X, Li X, et al. Of postoperative anal functions using endoanal ultrasonography and anorectal manometry in children with congenital anorectal malformations. J Pediatr Surg 2016;51:416-20.

[21] Hedlund H, Pena A, Rodriguez G, et al. Long-term anorectal function in imperforate anus treated by posterior sagittal anorectoplasty: manometric investigation. J Pediatr Surg 1992;27:906-9.

[22] Keshtgar AS, Athanasakos E, Clayden GS, et al. Evaluation of the outcome of anorectal anomaly in childhood: the role of anorectal manometry and endosonography. Pediatr Surg Int 2008;24:885-92.

[23] Bhat NA, Grover VP, Bhatnagar V. Manometric evaluation of postoperative patient with anorectal anomalies. Indian J Gastroenterol 2004;23:206-8.

[24] Rintala R. Postoperative internal sphincter function in anorectal malformations:a manometric study. Pediatr Surg Int 1990;5:127-30.

[25] Molander ML, Frenckner B. Anal sphincter function after surgery for high imperforate anus: a long term follow-up investigation. Z Kinderchir 1985;40:91-6.

[26] Doolin EJ, Black CT, Donaldson JS, et al. Rectal manometry, computed tomography and functional results of anal atresia surgery. J Pediatr Surg 1991;28:195-8.

[27] Taylor I, Duthie HL, Zachary RB. Anal continence following surgery for imperforate anus. J Pediatr Surg 1973;8:497-503.

[28] Kluth D, Hillen M, Lamprecht W. The principles of normal and abnormal hindgut development. J Pediatr Surg 1995;30:1143-7.

[29] Read MG, Read NW. Role of anorectal sensation in preserving continence. Gut 1982; 23:345-7.

[30] Broens PM, Penninckx FM, Boix Ochoa J. Fecal continence revisited: the anal external sphincter continence reflex. Dis Col Rectum 2013;56:1273-81.

[31] Borg H, Holmdahl G, Olsson I, et al. Impact of spinal cord malformation and bladder function in children with anorectal malformations. J Pediatr Surg 2009;44:1778-85.

[32] Kole MJ, Fridley JS, Jea A, et al. Currarino syndrome and spinal dysraphism. J Neurosurg Pediatr 2014;13:685-9. 